\title{
New entries for regio- and enantiopure syntheses of pyrrolidene systems fused to carbohydrate templates
}

\author{
Raed A. Al-Qawasmeh, ${ }^{\text {a }}$ Taleb H. Al-Telb, ${ }^{a}$ Khalid M. Khan ${ }^{b}$,Shahnaz Perveen, \\ and Wolfgang Voelter ${ }^{\mathrm{a}^{*}}$ \\ ${ }^{a}$ Interfakultäres Institut für Biochemie der Universität Tübingen, Hoppe-Seyler Straße 4, \\ D-72076, Tübingen, Germany \\ ${ }^{b}$ H.E.J. Research Institute of Chemistry, International Center for Chemical Sciences, \\ University of Karachi, Karachi-75270, Pakistan \\ ${ }^{\mathrm{c}}$ PCSIR Laboratories Complex, Shahrah-e-Dr. Salim-uz-Zaman Siddiqui, Karachi, \\ Karachi-75280, Pakistan \\ E-mail: wolfgang.voelter@uni-tuebingen.de
}

Dedicated to Professor Atta-ur-Rahman on the occasion of his $65^{\text {th }}$ birthday

\begin{abstract}
Facile syntheses of polysubstituted dihydro- and alkylidene tetrahydropyrrols using $\beta$ dimethylhydrazone esters and epoxy pyranosides are described.
\end{abstract}

Keywords: Epoxy sugars, pyrrolidenes, dihydropyrroles, $\beta$-ketoester hydrazones

\section{Introduction}

Polysubstituted tetrahydro- and dihydropyrroles with rich stereochemical functionalities are important targets either as a single entity ${ }^{1}$ or as substructures of many biological active molecules $^{2,3}$. Therefore, their synthesis has attracted the interest of many laboratories ${ }^{3}$.

A long-term objective of our research program has been to develop practical laboratory strategies for elaborating the epoxy pyranoside moiety ${ }^{4}$. Highlights of this program have included the development of new synthetic tactics for bis-cyclopentanoids, ${ }^{4 a}$ furanoids, ${ }^{4 b}$ oxazines or pyridazines $^{4 \mathrm{c}}$.

The chemistry of $\beta$-ketoester and/or 1,3-diketones continues to play a major role in synthetic design $^{5}$. Unfortunately, the major problem of $O$ - vs $C$-alkylation of such species plagues this important $\mathrm{C}-\mathrm{C}$ bond-forming process. In this regard, we have elaborated new synthons derived from carbohydrates and $\beta$-ketoesters ${ }^{4 \mathrm{~b}, 6}$. 
Recently, we have made numerous attempts to fuse cyclopentanoids to the carbohydrate framework, such as 3, via oxidation of the C-2 hydroxyl in the homologated pyranoside 2 , followed by intramolecular condensation (Scheme 1). Unfortunately we have been unable so far to carry out this reaction under a wide range of oxidizing agents ${ }^{7}$. An approach based on the Dess-Martin oxidation $^{8}$ has been similarly unfruitful. Interestingly, the hyperiodine reagent delivered $c a$. $10 \%$ of the enone 4 in which the alcohol function protected by the MOM group is eliminated. These results led to abandon the approach described here. However, mesylating the long-chain sugar $\mathbf{2}$, followed by reaction with $N, N^{\prime}$-dimethylhydrazine (DMH) ${ }^{9}$ delivered compound $\mathbf{5}$ which upon reaction with $\mathrm{NaH}$, produced quantitatively the pyrrolidene $\mathbf{7}$, but not the cyclopentanoid $\mathbf{6}$ as planned. Interestingly, $N$-alkylation overrode $C$-alkylation due to stereoelectronic considration $^{4 \mathrm{~b}, 6 \mathrm{a}}$, whereby, the anionic carbon cannot assume colinearity with the mesyl function (Scheme 1). The same reactions were performed with the isomeric sugar 8 to produce the pyrrolidene $\mathbf{1 0}$ in $95 \%$ yield (Scheme 2). These results reveal an interesting strategy for these bicyclic frameworks, representing new entries to enantiomerically pure pyrrolidene targets that have never been described before. The assignment of the stereochemistry around structure 7 is based on several key features. In the $400 \mathrm{MHz}{ }^{1} \mathrm{H}$ NMR spectrum of $(E)-7$, the allylic methylene protons (shifted downfield due to the anisotropic effect of the ester residue) of the tetrahydropyrrole ring resonate at $\delta=2.7$ and 3.39 as separate sets of doublet of doublet of doublets. The methine proton $\mathrm{H}-8$ resonates at $\delta=5.0$ as a doublet of doublets $(\mathrm{J}=0.9,1.5 \mathrm{~Hz})$ as result of coupling with the allylic methylene protons at C-6. In assigning the configuration of the double bond, we relied on the fact that doublet of doublets assigned to H-6 are more easily reconciled with a trans-alkene, since in the cis-case, coupling constants between $\mathrm{H}-8$ and the methylene proton are approximately zero ${ }^{4 b, 6 a}$. Furthermore, the stereochemistry around the double bond is also confirmed from the NOE experiments. Saturation of, both, H-8 and the dimethylamine residue, produced reciprocating NOE enhancements, further confirming the trans geometry of the exo-alkene function. On the other hand, irradiation of the C-6 protons showed no NOE enhancement of $\mathrm{H}-8$, further confirming the trans-geometry of the exo-alkene function. In addition, the ${ }^{13} \mathrm{C}$ NMR (GASPE) spectrum of 7 shows a methine carbon (C-8) resonance at 82 ppm which is relatively upfield shifted (located in the shielding region of the ester function) indicative for an $E$-configuration. The $400 \mathrm{MHz}{ }^{1} \mathrm{H}$ NMR spectrum of $(E)$-10 shows the same trends. Thus, the methylene protons of compound $\mathbf{1 0}$ occur as a separate set of doublet of doublets of doublets and are deshielded by the ester anisotropy $(\delta=2.72,3.28)$. The homoallylic coupling of vinyl proton $\mathrm{H}-8(\delta=5.0)$ is observed as a broad triplet $(\mathrm{J}=1.5 \mathrm{~Hz})$, indicative of an $E$-configuration for the exo-double bond. 


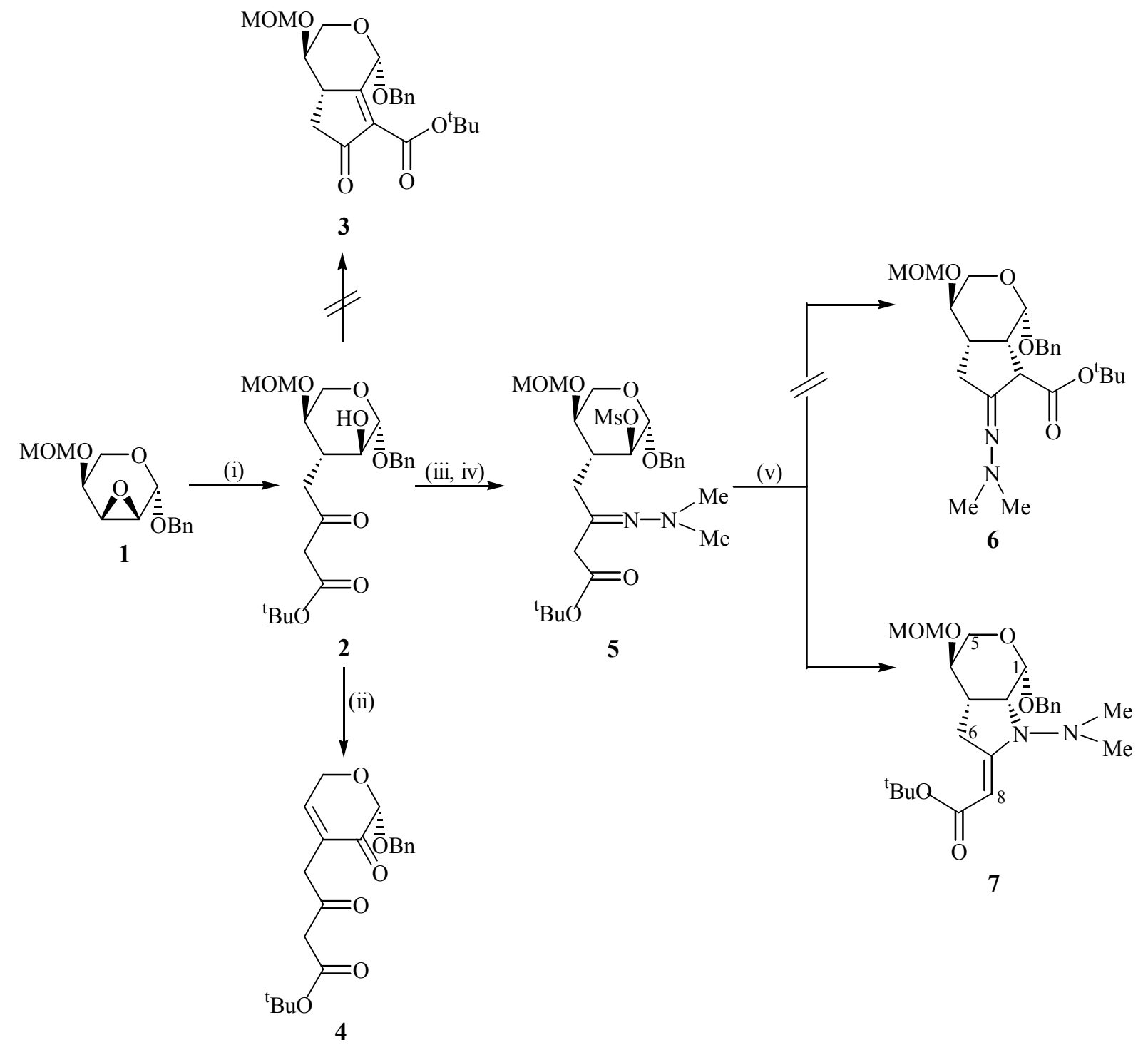

Scheme 1. Reagents and conditions: (i) ${ }^{t} \mathrm{Butyl}$ acetoacetate, $\mathrm{NaH},{ }^{n} \mathrm{BuLi}$ (3 equiv.), THF, $0{ }^{\circ} \mathrm{C} \rightarrow$ room temp., $5 \mathrm{~h}$, (ii) Dess Martin, (iii) $\mathrm{MsCl}, \mathrm{Et}_{3} \mathrm{~N}, \mathrm{CH}_{2} \mathrm{Cl}_{2},-15^{\circ} \mathrm{C}, 2 \mathrm{~h}$, (iv) $\mathrm{NH}_{2} \mathrm{NMe}_{2}, \mathrm{EtOH}$, $12 \mathrm{~h},(\mathrm{v}) \mathrm{NaH}, \mathrm{THF}, 0{ }^{\circ} \mathrm{C} \rightarrow$ room temp., $6 \mathrm{~h}$. 


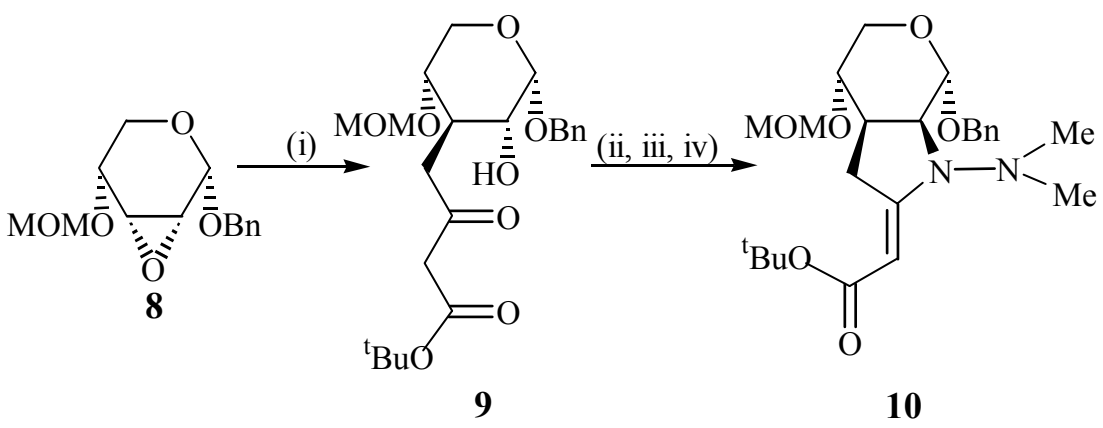

Scheme 2. Reagents and conditions: (i) ${ }^{t} \mathrm{Butyl}$ acetoacetate, $\mathrm{NaH},{ }^{n} \mathrm{BuLi}$ (3 equiv.), THF, $0{ }^{\circ} \mathrm{C} \rightarrow$ room temp., $5 \mathrm{~h}$, (ii) $\mathrm{MsCl}, \mathrm{Et}_{3} \mathrm{~N}, \mathrm{CH}_{2} \mathrm{Cl}_{2},-15{ }^{\circ} \mathrm{C}, 2 \mathrm{~h}$, (iii) $\mathrm{NH}_{2} \mathrm{NMe}_{2}, \mathrm{EtOH}, 12 \mathrm{~h}$, (iv) $\mathrm{NaH}$, THF, $0{ }^{\circ} \mathrm{C} \rightarrow$ room temp., $6 \mathrm{~h}$.

Extending our work on $\beta$-ketoesters-DMH tactics for the construction of polyfunctionalized azacycles, we treated the epoxy triflate $\mathbf{1 1}$ with the monoanion of $\mathbf{1 2}$ (formed by condensing asymmetric $\mathrm{DMH}$ wit tert-butyl acetoacetate in $\mathrm{EtOH}$ ) to produce the polysubstituted dihydopyrrolidene 14 in $86 \%$ yield (Scheme 3). Interestingly, the ring-closure is taking place via $N$-alkylation, whereby the nitrogen nucleophile can assume colinearity for the intramolecular $\mathrm{S}_{N} 2$ nucleophlic ring opening of the oxirane ring. On the other hand, compound $\mathbf{1 3}$ is not observed (Scheme 3).

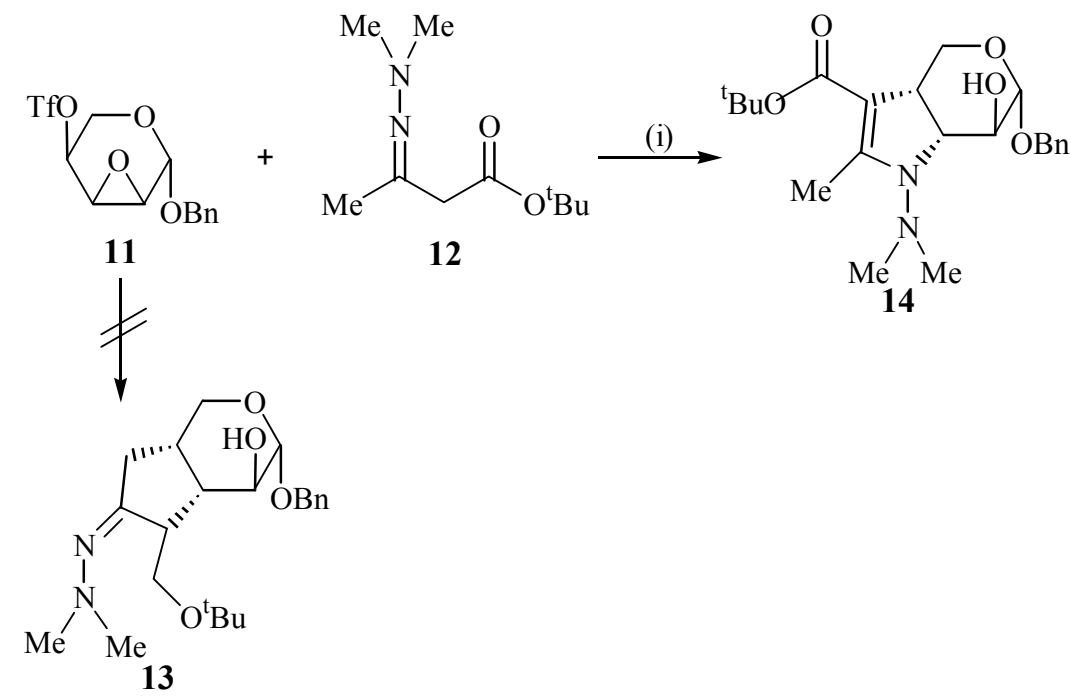

Scheme 3. Reagents and conditions: (i) 12 , THF, 1.1 equiv. $\mathrm{NaH}, 0{ }^{\circ} \mathrm{C} \rightarrow$ room temp., $1 \mathrm{~h}$, then $11,0{ }^{\circ} \mathrm{C} \rightarrow$ room temp., $5 \mathrm{~h}$.

It seems that the double $C$-alkylation process is not feasible due to stereoelctronic considerations. The ${ }^{1} \mathrm{H}$ NMR spectrum of $\mathbf{1 4}$ shows a doublet of doublet $(\mathrm{J}=5.1,9.5 \mathrm{~Hz})$ assigned to the heteroatom ring proton $(\mathrm{H}-3)$. A salient feature of the ${ }^{1} \mathrm{H}$ NMR spectrum of the 
dihydropyrrolidene 14 is the two singlets at 2.57 and $2.16 \mathrm{ppm}$, assigned to the $\mathrm{N}\left(\mathrm{CH}_{3}\right)_{2}$ and $\mathrm{CH}_{3}-7$ protons, respectively. Interestingly, in the ${ }^{13} \mathrm{C} \mathrm{NMR}$ of 14 , we were unable to detect a $\mathrm{N}\left(\mathrm{CH}_{3}\right)$ resonance, although the ${ }^{1} \mathrm{H} \mathrm{NMR}, \mathrm{FD}, \mathrm{FAB}$ and $\mathrm{EI}$ analysis indicate the presence of this residue. This phenomenon may be due to the dihydropyrrolidene framework coupled with long spin-lattice relaxation time of $\mathrm{N}-\mathrm{N}\left(\mathrm{CH}_{3}\right)_{2}$ rotamers. Furthermore, the ${ }^{1} \mathrm{H} /{ }^{13} \mathrm{C} \mathrm{COSY}$ spectrum of 14 indicates that the broad singlet at $2.57 \mathrm{ppm}$, assigned to $\mathrm{N}\left(\mathrm{CH}_{3}\right)_{2}$ in the ${ }^{1} \mathrm{H} \mathrm{NMR}$, is connected to the region around $43 \mathrm{ppm}$ in the ${ }^{13} \mathrm{C}$ NMR spectrum. The presence of the signals at 163.2 and 100.2 ppm (assigned for C-7 and C-6, respectively) in the ${ }^{13} \mathrm{C} N M R$ spectrum of 14 further confirm the dihydropyrrolidene skeleton. The versatility and feasibility of our new methodology is expanded at present time to produce different dihydropyrrolidene systems with different functionality and stereochemistry.

In conclusion, the chemistry described here, represents new and economic entries to polyfunctionalized pyrrolidene systems, fused to pyranoside skeletons with the further aim to expand this strategy to other targets. Furthermore, the integration of our new synthons to the synthesis of natural molecules is under way in our laboratories.

\section{Acknowledgements}

DAAD is gratefully acknowledged for awarding Visiting Professor and $\mathrm{PhD}$ scholarships to THA, KMK, SP and RAA, respectively. We also thank Fonds der Chemischen Industrie for financial support.

\section{Experimental Section}

General Procedures. All chemicals were purchased from Sigma-Aldrich and used as received. ${ }^{1} \mathrm{H}$ NMR spectra were recorded in $\mathrm{CD}_{3} \mathrm{OD}$ or $\mathrm{CDCl}_{3}$ on a Bruker Aspect AM-400 spectrometer operating at $400 \mathrm{MHz}$ using 1\% TMS as an internal standard. Splitting patterns are given follows: s, singlet; $d$, doublet; dd, double doublet; t, triplet; q, quartet; m, multiplet. Chemical shifts are reported in $\delta(\mathrm{ppm})$ and coupling constants are given in Hz. FD mass spectra (FDMS) were determined on a Finnigan MAT-312 spectrometer. The progress of all reactions was monitored using $2 \times 5 \mathrm{~cm}$ glass plates precoated with silica gel $60 \mathrm{~F}_{254}$ to a thickness of $0.25 \mathrm{~mm}$. The chromatograms were visualized under ultraviolet light (where appropriate) sprayed with an orcinol $/ \mathrm{H}_{2} \mathrm{SO}_{4} / \mathrm{FeCl}_{3}$ solution and heated to develop. Optical rotations were obtained with an LEP AZ polarimeter (Zeiss, Jena) at $546 \mathrm{~nm}$. All melting points are uncorrected.

General procedure for alkylidene tetrahydropyrrole syntheses. To a suspension of $3.0 \mathrm{mmol}$ of $\mathrm{NaH}\left(65 \%\right.$ dispersion in paraffin oil) in THF $(10 \mathrm{ml})$ under argon at $0{ }^{\circ} \mathrm{C}$ was added tert-butyl acetoacetate $(3.0 \mathrm{mmol})$ over a period of $10 \mathrm{~min}$. The mixture was stirred for another $30 \mathrm{~min}$ at 
the same temperature followed by dropwise addition of $3.0 \mathrm{mmol}$ of $n$-BuLi (1.6 M in hexane). The resultant milky mixture was stirred at $0{ }^{\circ} \mathrm{C}$ for $45 \mathrm{~min}$ followed by the addition of 1 (1.0 $\mathrm{mmol})$ in THF (5 ml). The mixture was warmed to room temperature and stirring was continued for 4-5 $\mathrm{h}$. After completion of the reaction (TLC analysis), the mixture was quenched with saturated $\mathrm{NH}_{4} \mathrm{Cl}(5 \mathrm{ml})$, diluted with $\mathrm{H}_{2} \mathrm{O}(10 \mathrm{ml})$ and extracted with EtOAc $(2 \times 20 \mathrm{ml})$. The combined organic layers were washed with brine, dried over anhydrous $\mathrm{Na}_{2} \mathrm{SO}_{4}$ and evaporated under vacuum. The crude product was filtered on a short silica gel column using EtOAc/ $\mathrm{CH}_{2} \mathrm{Cl}_{2}$ (5-10\%) as eluent to give $96 \%$ yield of compound 2. To a solution of $2(1 \mathrm{mmol})$ in $\mathrm{CH}_{2} \mathrm{Cl}_{2}(5$ $\mathrm{ml})$, containing $\mathrm{Et}_{3} \mathrm{~N}(1.2 \mathrm{mmol})$ and 4-(dimethylamino)pyridine $(0.1 \mathrm{mmol})$, at $-15{ }^{\circ} \mathrm{C}$ was added $\mathrm{MsCl}(1.2 \mathrm{mmol})$ and stirred for $2 \mathrm{~h}$. The mixture was quenched by adding $5 \mathrm{ml}$ of a saturated solution of $\mathrm{NaHCO}_{3}$, extracted with $\mathrm{CH}_{2} \mathrm{Cl}_{2}(2 \times 10 \mathrm{ml})$, dried over anhydrous $\mathrm{Na}_{2} \mathrm{SO}_{4}$, evaporated to dryness and used in the next step without further purification. To a solution of the resulting mesylate $(1 \mathrm{mmol})$ in absolute ethanol $(5 \mathrm{ml})$ was added asymmetric $N, N$ dimethylhydrazine $(5 \mathrm{mmol})$ in ethanol $(1 \mathrm{ml})$. The reaction was stirred at room temperature for $12 \mathrm{~h}$ and evaporated under vacuum to afford compound 5 . To a suspension of $1.2 \mathrm{mmol} \mathrm{NaH}$ (65\% dispersion in paraffin oil) in THF $(10 \mathrm{ml})$ at $0{ }^{\circ} \mathrm{C} 5(1 \mathrm{mmol})$ in THF $(2 \mathrm{ml})$ was added. The reaction mixture was stirred at room temperature for $6 \mathrm{~h}$, quenched with a saturated solution of $\mathrm{NH}_{4} \mathrm{Cl}(5 \mathrm{ml})$ and extracted with EtOAc $(2 \times 20 \mathrm{ml})$. The extracts were dried over anhydrous $\mathrm{Na}_{2} \mathrm{SO}_{4}$, evaporated and filtered over silica gel using $\mathrm{CH}_{2} \mathrm{Cl}_{2}$ as an eluent to give $96 \%$ yield of compound 7. Selected data of 7: $[\alpha]^{\mathrm{D}}{ }_{20}+85.1^{\circ}\left(c 0.3, \mathrm{CH}_{2} \mathrm{Cl}_{2}\right)$; FD-MS $(\mathrm{m} / \mathrm{z}) 448\left(\mathrm{M}^{+}\right) ;{ }^{1} \mathrm{H}$ $\delta_{(\mathrm{ppm})}:$ 7.27-7.22 (m, 5H,Ph), 5.0 (dd, J=0.9, $\left.1.5 \mathrm{~Hz}, 1 \mathrm{H}, \mathrm{H}-8\right), 4.98$ (d, J=4.3 Hz, 1H, H-1), 4.72 (d, J=12.3 Hz, 1H, CHHPh), 4.71 (d, J=7.1 Hz, 1H, OCHHO), 4.67 (d, J=7.1 Hz, 1H, OCHHO), 4.37 (d, J=12.3 Hz, 1H, OCHHPh), 3.99 (dd, J=4.3, 7.4 Hz, 1H, H-2), 3.82 (dd, J=1.5, $12.8 \mathrm{~Hz}$, 1H, H-5), 3.71 (bs, 1H, H-4), 3.59 (dd, J=1.7, 12.8 Hz, 1H, H-5'), 3.39 (ddd, J=1.0, 8.0, 17.0 Hz, 1H, H-6), 3.36 (s, 3H, OCH $), 2.70$ (ddd, J=5.0, 12.8, 17.0 Hz, 1H, H-6'). 2.43 (bs, 6H, $\left.\mathrm{N}\left(\mathrm{CH}_{3}\right)_{2}, 2.33(\mathrm{~m}, 1 \mathrm{H}, \mathrm{H}-3), 1.46\left(\mathrm{~s}, 9 \mathrm{H}, \mathrm{C}\left(\mathrm{CH}_{3}\right)_{3}\right) ;{ }^{13} \mathrm{C} \delta_{(\mathrm{ppm})}\right): 169.6\left(\mathrm{CO}_{2} t-\mathrm{Bu}\right), 161.4(\mathrm{C}-7)$, 136.7, 128.3, 127.4, $126.9(\mathrm{Ph}), 96.9(\mathrm{C}-1), 94.9\left(\mathrm{OCH}_{2} \mathrm{O}\right), 82.0(\mathrm{C}-8), 77.4\left(\mathrm{C}\left(\mathrm{CH}_{3}\right)_{3}\right), 71.3(\mathrm{C}-$ 4), $\left.68.8\left(\mathrm{OCH}_{2} \mathrm{Ph}\right), 56.6(C-5), 55.4(\mathrm{OCH} 3), 52.1(\mathrm{C}-2), 43.0\left(\mathrm{~N}_{(\mathrm{CH}}\right)_{2}\right), 37.1(\mathrm{C}-3), 32.7(\mathrm{C}-6)$, $28.7\left(\mathrm{CCH}_{3}\right.$ ). (Found: $\mathrm{C}, 64.33 ; \mathrm{H}, 8.15 ; \mathrm{N}, 6.22 ; \mathrm{C}_{24} \mathrm{H}_{36} \mathrm{~N}_{2} \mathrm{O}_{6}$ requires $\mathrm{C}, 64.26 ; \mathrm{H}, 8.09 ; \mathrm{N}$, 6.25).

Selected data for 10. $[\alpha]_{20}^{\mathrm{D}}+78.8^{\circ}\left(c 0.34, \mathrm{CH}_{2} \mathrm{Cl}_{2}\right)$; FD-MS $(\mathrm{m} / \mathrm{z}) 448\left(\mathrm{M}^{+}\right) ;{ }^{1} \mathrm{H} \delta_{(\mathrm{ppm})}:$ 7.347.30 (m, 5H, Ph), 5.0 (bd, J=1.5 Hz, 1H, H-8), 4.76 (d, J=11.5, 1H, CHHPh), 4.71 (d, J=7.1 Hz, 1H, OCHHO), 4.68 (d, J=7.1 Hz, 1H, OCHHO), 4.64 (d, J=3.1 Hz, 1H, H-1), 4.49 (d, J=11.5 Hz, 1H, OCHHPh), 3.85 (dd, J=4.4, $11.5 \mathrm{~Hz}, 1 \mathrm{H}, \mathrm{H}-5), 3.80$ (dd, J=3.1, 6.6 Hz, 1H, H-2), 3.72 (dd, $\mathrm{J}=8.9,11.5 \mathrm{~Hz}, 1 \mathrm{H}, \mathrm{H}-5$ '), 3.55 (ddd, J=4.4, 6.5, $8.9 \mathrm{~Hz}, 1 \mathrm{H}, \mathrm{H}-4), 3.36$ (s, $3 \mathrm{H}, \mathrm{OCH}_{3}$ ), 3.28 (ddd, J=1.0, 6.7, $17.0 \mathrm{~Hz}, 1 \mathrm{H}, \mathrm{H}-6$ ), 2.72 (ddd, J=1.5, 10.1, 17.0 Hz, 1H, H-6'), 2.55 (bs, 6H, $\left.\mathrm{N}\left(\mathrm{CH}_{3}\right)_{2}\right), 2.34(\mathrm{~m}, 1 \mathrm{H}, \mathrm{H}-3), 1.42\left(\mathrm{~s}, 9 \mathrm{H}, \mathrm{C}\left(\mathrm{CH}_{3}\right)_{3}\right) ;{ }^{13} \mathrm{C} \delta_{(\mathrm{ppm})}: 169.0\left(\mathrm{CO}_{2} t-\mathrm{Bu}\right), 160.0(\mathrm{C}-7)$, 137.3, 128.4, 127.9, $127.8(P h), 97.7(C-1), 97.2\left(\mathrm{OCH}_{2} \mathrm{O}\right), 84.6(C-8), 77.8\left(C\left(\mathrm{CH}_{3}\right)_{3}\right), 74.9(C-$ 4), $\left.69.4\left(\mathrm{OCH}_{2} \mathrm{Ph}\right), 60.6(C-5), 55.7\left(\mathrm{OCH}_{3}\right), 58.1(C-2), 42.0\left(\mathrm{~N}_{(\mathrm{CH}}\right)_{2}\right), 39.7(C-3), 29.6(C-6)$, 
$28.6\left(\mathrm{C}\left(\mathrm{CH}_{3}\right)_{3}\right)$. (Found: $\mathrm{C}, 63.91 ; \mathrm{H}, 7.78 ; \mathrm{N}, 6.34 ; \mathrm{C}_{24} \mathrm{H}_{36} \mathrm{~N}_{2} \mathrm{O}_{6}$ requires $\mathrm{C}, 64.26 ; \mathrm{H}, 8.09 ; \mathrm{N}$, $6.25)$.

\section{Procedure for dihydropyrrole syntheses}

To a suspension of $3.3 \mathrm{mmol}$ of $\mathrm{NaH}, 65 \%$ dispersion in paraffin oil, in THF (10 ml) under argon at $0{ }^{\circ} \mathrm{C}$ the $\beta$-dimethylhydrazone ester $12(3.0 \mathrm{mmol})$ was added over a period of $10 \mathrm{~min}$. The mixture was stirred for $1 \mathrm{~h}$ at the same temperature, followed by the addition of 11 (1 mmol) in THF $(2 \mathrm{ml})$ at $0{ }^{\circ} \mathrm{C}$ and kept for $5 \mathrm{~h}$ at room temperature. The reaction was quenched with a saturated solution of $\mathrm{NH}_{4} \mathrm{Cl}(5 \mathrm{ml})$, extracted with EtOAc $(2 \times 20 \mathrm{ml})$, dried over anhydrous $\mathrm{Na}_{2} \mathrm{SO}_{4}$ and concentrated under vacuum to afford crude 14. The crude product was further purified on a short silica gel column using EtOAc/ $\mathrm{CH}_{2} \mathrm{Cl}_{2}(5-10 \%)$ as eluent to afford compound 14 in $95 \%$ yield. Selected data of 14: $[\alpha]_{20}^{\mathrm{D}}+143.5^{\circ}\left(c 0.31, \mathrm{CH}_{2} \mathrm{Cl}_{2}\right)$; FD-MS (m/z) $404\left(\mathrm{M}^{+}\right)$; ${ }^{1} \mathrm{H} \delta_{(\mathrm{ppm})}: 7.32-7.28(\mathrm{~m}, 5 \mathrm{H}, P h), 4.79(\mathrm{~d}, \mathrm{~J}=11.4 \mathrm{~Hz}, 1 \mathrm{H}, \mathrm{CHH} \underline{P h}), 4.76(\mathrm{~d}, \mathrm{~J}=4.5 \mathrm{~Hz}, 1 \mathrm{H}, \mathrm{H}-1)$, 4.49 (d, J=11.4 Hz, 1H, OCHHPh), 3.94 (t, J=4.5 Hz, 1H, H-2), 3.84 (dd, J=6.4, 10.8 Hz, 1H, H5), 3.68 (dd, J=5.1, 9.5 Hz, 1H, H-3), 3.62 (t, J=10.8 Hz, 1H, H-5'), 3.32 (m, 1H, H-4), 2.57 (bs, $\left.\left.6 \mathrm{H}, \mathrm{N}\left(\mathrm{CH}_{3}\right)_{2}\right), 2.16\left(\mathrm{~s}, 3 \mathrm{H}, \mathrm{CH}_{3}-7\right)\right), 1.44\left(\mathrm{~s}, 9 \mathrm{H}, \mathrm{C}\left(\mathrm{CH}_{3}\right)_{3}\right) ;{ }^{13} \mathrm{C} \delta_{(\mathrm{ppm})}: 166.0\left(\mathrm{CO}_{2} t-\mathrm{Bu}\right), 163.2(C-$

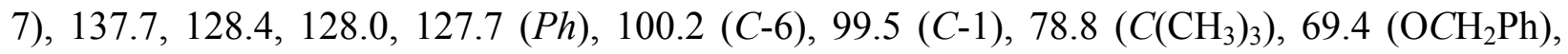
$68.2(C-2), 61.0(C-5), 60.2(C-3), 42.0\left(\mathrm{~N}\left(\mathrm{CH}_{3}\right)_{2}\right), 38.0(C-4), 28.7\left(\mathrm{C}_{\left.\left(C \mathrm{H}_{3}\right)_{3}\right),} 12.9(C-8)\right.$.

(Found: C, 65.27; H, 8.03; N, 6.97; $\mathrm{C}_{22} \mathrm{H}_{32} \mathrm{~N}_{2} \mathrm{O}_{5}$ requires $\mathrm{C}, 65.32 ; \mathrm{H}, 7.97 ; \mathrm{N}, 6.93$ ).

\section{References}

1. (a) Aly, M.F., Ardill, H., Grigg, R., Leong-Ling, S., Rajviroongit, S., Surendrakumar, S. Tetrahedron Lett., 1987, 28, 6077.; (b) Gotthardt, H., Husigen, R., Chem. Ber., 1970,103, 2625.; (c) Friedrichsen, W., Schröer, W.-D. Tetrahedron Lett., 1977, 19, 1603.; (d) Woller, P.B., Cromwell, N.H. J. Org. Chem., 1970, 35, 888.

2. (a) Cossy, J., Cases, M., Gomez-Pardo, D. Synlett, 1998, 507.; (b) Peterson, J.S., Fels, G., Rapoport, H. J. Am. Chem. Soc., 1984, 106, 4539.; (c) Gelb, M.H., Svaren, J.P., Abeles, R.H. Biochemistry, 1985, 24, 1813.

3. (a) Hart, D.J., Sun, L.-Q., Kozikowski, A.P. Tetrahedron Lett., 1995, 36, 7787.; (b) Davis, B., Brandstetter, T.W., Smith, C., Hackett, L., Winchester, B.G., Fleet, G.W.J. Tetrahedron Lett., 1995, 36, 7507.; (c) Gaebert, C., Mattay, J. Tetrahedron, 1997, 53, 14297.; (d) Chapleur, Y. in Carbohydrate Mimics: Concepts and Methods, ed. Y. Chapleur, WileyVCH, Weinheim, 1997.

4. (a) Naz, N., Al-Tl, T.H., Al-Abed, Y., Voelter, W., Ficker, R., Hiller, W. J. Org. Chem., 1996, 61, 3250.; (b) Al-Tel, T.H., Voelter, W. J. Chem. Soc. Chem. Commun., 1995, 239, and references cited therein; (c) Al-Tel, T.H., Meisenbach, M., Voelter, W. Liebigs. Ann. Chem., 1995, 689.; (d) Al-Qawasmeh, R.A., Al-Tel, T.H., Abdel-Jalil, R.J., Voelter, W. Chem. Lett., 1999, 541.

5. Benetti, S., Romagnoli, R., De Risi, C., Spalluto, G., Zanirato, V. Chem. Rev., 1995, 95, 1065 
6. (a) Al-Tel, T.H., Voelter, W. Tetrahedron Lett., 1995, 36, 523.; (b) Al-Tel, T.H., Al- Abed, Y., Voelter, W. J. Chem. Soc. Chem., 1994, 1735.

7. (a) Pipelier, M., Ermolenko, M.S., Zampella, A., Olesker A., Lukacs, G. Synlett, 1996, 24.; (b) Butterworth, R.F., Hanessian, S. Synthesis, 1971, 70.; (c) Griffith, W.P., Ley, S.V. Aldrichimicha Acta, 1990, 23, 13.

8. (a) Dess, D.B., Martin, J.C. J. Org. Chem., 1983, 48, 4155.; (b) Dess, D.B., Martin, J.C. J. Am. Chem. Soc., 1991, 113, 7277.

9. Corey, E.J., Enders, D. Tetrahedron Lett., 1976, 18, 11. 